\title{
Impact of early coronary angiography on the survival to discharge after out- of-hospital cardiac arrest
}

\author{
Jikyoung Shin, Eunsil Ko, Won Chul Cha, Tae Rim Lee, Hee Yoon, \\ Sung Yeon Hwang, Tae Gun Shin, Min Seob Sim, Ik Joon Jo, \\ Keun Jeong Song, Joong Eui Rhee, Yeon Kwon Jeong, Jin-Ho Choi \\ Department of Emergency Medicine, Samsung Medical Center, Sungkyunkwan University School of \\ Medicine, Seoul, Korea
}

Objective Acute myocardial infarction is a major cause of out-of-hospital cardiac arrest (OHCA). Coronary angiography (CAG) enables diagnostic confirmation of coronary artery disease and subsequent revascularization, which might improve the prognosis of OHCA survivors. Non-randomized data has shown a favorable impact of CAG on prognosis for this population. However, the optimal timing of CAG has been debated.

Methods The clinical outcomes of 607 OHCA patients registered in CAPTURES (Cardiac Arrest Pursuit Trial with Unique Registration and Epidemiologic Surveillance), a nationwide multicenter registry performed in 27 hospitals, were analyzed. Early CAG was defined as CAG performed within 24 hours of emergency department admission. The primary outcome was survival to discharge, with neurologically favorable status defined by cerebral performance category scores $\leq 2$.

Results Compared to patients without CAG ( $n=469)$, patients who underwent early CAG $(n=138)$ were younger, more likely to be male, and more likely to have received bystander cardiopulmonary resuscitation, pre-hospital defibrillation, and revascularization ( $\mathrm{P}<0.01$ for all). Analysis of 115 propensity score-matched pairs showed that early CAG is associated with a 2.3-fold increase in survival to discharge with neurologically favorable status $(P<0.001$, all). Survival to discharge increased consistently according to the time interval between emergency department visit and CAG $(P<0.05)$.

Conclusion Early CAG of OHCA patients was associated with better survival and favorable neurologic outcomes at discharge. However, there was no clear time threshold for CAG that predicted survival to discharge.

Keywords Early coronary angiography; Out-of-hospital cardiac arrest; Survival rate; Neurologic outcome
eISSN: 2383-4625

Received: 26 February 2017

Revised: 18 April 2017

Accepted: 8 May 2017

Correspondence to: Jin-Ho Choi Department of Emergency Medicine, Samsung Medical Center,

Sungkyunkwan University School of Medicine, 81 Irwon-ro, Gangnam-gu, Seoul 06351, Korea

E-mail: jhchoimd@gmail.com

Won Chul Cha

Department of Emergency Medicine, Samsung Medical Center,

Sungkyunkwan University School of Medicine, 81 Irwon-ro, Gangnam-gu, Seoul 06351, Korea

E-mail:wc.cha@samsung.com

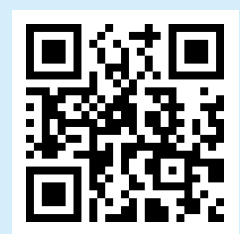

How to cite this article:

Shin J, Ko E, Cha WC, Lee TR, Yoon $\mathrm{H}_{\text {, }}$ Hwang SY, Shin TG, Sim MS, Jo IJ, Song KJ, Rhee JE, Jeong YK, Choi JH. Impact of early coronary angiography on the survival to discharge after out-of-hospital cardiac arrest. Clin Exp Emerg Med 2017;4(2):65-72.

This is an Open Access article distributed under the terms of the Creative Commons Attribution Non-Commercial License (http:// creativecommons.org/licenses/by-nc/4.0/). 


\begin{tabular}{|c|c|}
\hline $\begin{array}{l}\text { Capsule } \\
\text { Summary }\end{array}$ & $\begin{array}{l}\text { What is already known } \\
\text { Early coronary angiography after out-of-hospital cardiac arrest enables diagnostic confirmation of coronary artery dis- } \\
\text { ease and subsequent revascularization, which might improve the prognosis of out-of-hospital cardiac arrest survivors. } \\
\text { However, clinical research on the topic is limited and the optimal timing of coronary angiography after cardiac arrest is } \\
\text { not yet known. }\end{array}$ \\
\hline & $\begin{array}{l}\text { What is new in the current study } \\
\text { This nationwide multicenter study showed that early coronary angiography within } 24 \text { hours of admission was associat- } \\
\text { ed with better survival and neurologic outcomes after out-of-hospital cardiac arrest. There was no clear threshold in } \\
\text { the timing of early coronary angiography. }\end{array}$ \\
\hline
\end{tabular}

\section{INTRODUCTION}

Sudden cardiac death is a major complication of coronary artery vascular disease. ${ }^{1,2}$ Current clinical guidelines recommend immediate coronary angiography (CAG) after return of spontaneous circulation (ROSC) for out-of-hospital cardiac arrest (OHCA) patients presenting with ST segment elevation. ${ }^{3}$ Even when there is no evidence of cardiac cause, CAG is recommended within 2 hours of admission after ROSC. ${ }^{4}$ However, early identification of acute myocardial ischemia by electrocardiography in the setting of OHCA is challenging. ${ }^{5-7}$ Performing CAG early in such clinical situations might enable early diagnostic confirmation of coronary artery disease and subsequent revascularization or hemodynamic support, thereby improving clinical outcomes. Prior clinical studies have shown improved clinical outcomes after CAG in OHCA patients. ${ }^{7-9}$ However, most of these studies lack controls and a multicenter-study design. The optimal timing of CAG after OHCA in patients without ST segment elevation is still debated. We investigated the effect of early CAG after OHCA using a large nationwide $\mathrm{OHCA}$ registry in Korea.

\section{METHODS}

\section{Patients}

The Cardiac Arrest Pursuit Trial with Unique Registration and Epidemiologic Surveillance (CAPTURES) is a prospective, nationwide, multicenter, and dynamic registry of OHCA aimed at identifying the etiology of acute cardiac arrest in Korea. CAPTURES collects data on all emergency medical service (EMS) activated OHCA events without a definite non-cardiac cause of arrest, such as major trauma or end-stage malignancy. The registry includes data regarding patient clinical characteristics, pre-hospital time variables, and in-hospital outcomes at enrolling sites. From March 2014 to December 2014, a total of 1,616 OHCA patients were identified from 27 hospitals. Patients were excluded if they did not achieve ROSC
( $n=883)$, were aged $<18$ years $(n=19)$, were not transferred by EMS $(n=4)$, or had incomplete data $(n=45)$. Patients with sustained ROSC and sinus rhythm did not have important clinical variables recorded before emergency department (ED) arrival and were therefore excluded on the basis of incomplete data. In addition, patients who underwent CAG after 24 hours were considered as requiring "non-urgent $C A G$ " and were not included $(n=58)$. Therefore, a total of 607 patients were enrolled in the study (Fig. 1).

\section{Clinical variables}

Pre-hospital patient-level data including age, sex, location of arrest (public, home, or healthcare), witnessed state, provision of bystander cardiopulmonary resuscitation, pre-hospital defibrillation, and pre-hospital electrocardiography, dichotomized as shockable or non-shockable rhythm, were assessed. The time of the EMS call, EMS arrival, and arrival to ED were assessed and used for calculations of response time (from EMS call to EMS arrival), transfer time (from EMS arrival to ED arrival), and ROSC time (from EMS call time to ROSC).

In-hospital data included intubated status, use of intravenous inotropic agents, therapeutic hypothermia, time from ED arrival to $C A G$, mechanical circulatory support, which included an intraaortic balloon pump and extracorporeal membrane oxygenation, and revascularization, which included the use of thrombolytic agents, percutaneous coronary revascularization, and bypass surgery. Cardiovascular risk factors, including diabetes, hypertension, and current smoking status, were also assessed.

Early CAG was defined as CAG performed within 24 hours of arrival to ED. The primary endpoint was survival to discharge with favorable neurological status, defined by cerebral performance category scores $\leq 2$ within 90 days. ${ }^{10}$ The secondary outcome was survival to discharge within 90 days.

\section{Statistical analysis}

Continuous parameters are expressed as median (1st to 3rd quar- 


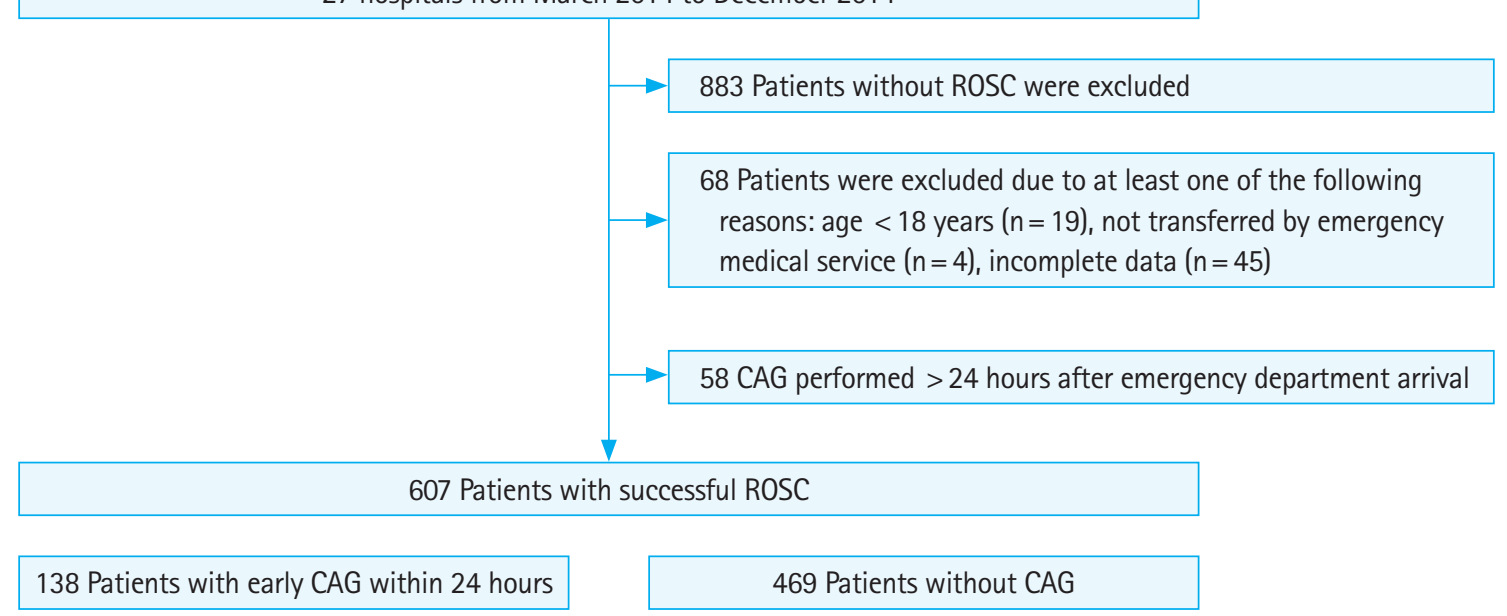

Fig. 1. Study flow. OHCA, out-of-hospital cardiac arrest; CAPTURES, Cardiac Arrest Pursuit Trial with Unique Registration and Epidemiologic Surveillance; $C A G$, coronary angiography; ROSC, return of spontaneous circulation.

tiles). Continuous and categorical parameters were compared using the Mann-Whitney U-test or Fisher's exact test, as appropriate. The clinical outcomes of patients with early CAG and patients without CAG were compared using Cox's proportional hazard model and logistic regression and expressed as hazard ratios (HR) and odds ratios (OR). The dose-response relationship between CAG time and survival was assessed by the Jonckheere-Terpstra test for trend. Both unadjusted data and propensity score-matched data, based on the predicted probability of being assigned to early CAG, were analyzed. The propensity score-matched dataset was created by using propensity scores calculated with the following covariates: age, sex, location of arrest, bystander cardiopulmonary resuscitation, pre-hospital defibrillation, ROSC time, intubation, use of inotropic agents, and hypothermia. These clinical variables showed statistically significant differences between the two groups by univariate analysis, as shown in Table 1. The survival analysis was conducted using ED arrival to discharge time or death time to distinguish between patients who underwent early CAG or no CAG. R ver. 3.2.5 (R Foundation for Statistical Computing, Vienna, Austria) was used for all statistical analyses. Statistical significance was defined by a two-tailed P-value $<0.05$.

\section{RESULTS}

Compared to patients without CAG $(n=469,77 \%)$, patients who underwent early CAG within 24 hours $(n=138,23 \%)$ were younger (median age, 58 vs. 65 years), more likely to be male ( $89 \%$ vs. $66 \%)$, and more likely to be treated by bystander cardiopulmonary resuscitation (56\% vs. $42 \%)$, pre-hospital defibrillation (72\% vs. $27 \%$ ), and revascularization (50\% vs. $3 \%$ ) (Table 1). The unadjusted rates of survival to discharge and neurologically favorable discharge were higher in patients with early CAG compared to patients without CAG (66\% vs. $22 \%$ and $52 \%$ vs. $10 \%$, respectively; $\mathrm{P}<0.001$ for all) (Table 2).

To reduce confounding and indication bias, 115 propensity scorematched pairs were prepared based on the predicted probability of being assigned to early CAG (Table 3). The appropriateness of matching was confirmed by achieving covariate balance between both groups. Superior clinical outcomes of patients with early CAG compared with patients without CAG persisted after propensity score-matched analysis (62\% vs. $37 \%$ and $49 \%$ vs. $20 \%$, respectively; $\mathrm{P}<0.001$ for all) (Table 4). These clinical outcomes are depicted in Fig. 2.

Survival analysis showed that early CAG was associated with more than a 3-fold increase in survival to discharge with neurologically favorable status or survival to discharge alone (HR, 3.6; 95\% confidence interval [CI], 2.8 to $4.7 ; 0 \mathrm{O}, 6.8 ; 95 \% \mathrm{Cl}, 4.5$ to 0.3 and $\mathrm{HR}, 4.0 ; 95 \% \mathrm{Cl}, 3.0$ to $5.5 ; \mathrm{OR}, 10.5 ; 95 \% \mathrm{Cl}, 6.8$ to 16.6 , respectively; $\mathrm{P}<0.001$, all). In the analysis of propensity-matched pairs, early CAG showed a 2-fold increase in survival to discharge with neurologically favorable status or survival to discharge alone ( $\mathrm{HR}, 2.3 ; 95 \% \mathrm{Cl}, 1.6$ to $3.3 ; \mathrm{OR}, 3.8 ; 95 \% \mathrm{Cl}, 2.1$ to 6.8 and $\mathrm{HR}$, $2.3 ; 95 \% \mathrm{Cl}, 1.6$ to $3.1 ; \mathrm{OR}, 2.7 ; 95 \% \mathrm{Cl}, 1.6$ to 4.6 , respectively; $\mathrm{P}<0.001$ for all) (Table 5).

The timing of early CAG and survival to discharge are shown in Fig. 3. Most (78\%) early CAGs were performed within 3 hours of ED arrival. Interestingly, there was a significant increase in survival to discharge according to the time interval between ED ar- 
Table 1. Pre-hospital clinical characteristics and hospital course

\begin{tabular}{|c|c|c|c|}
\hline & Early CAG $(n=138)$ & No CAG $(n=469)$ & P-value \\
\hline \multicolumn{4}{|l|}{ Pre-hospital presentation } \\
\hline Age (yr) & $58(50-68)$ & $65(52-77)$ & 0.001 \\
\hline Sex, male & $123(89)$ & $307(66)$ & $<0.001$ \\
\hline \multicolumn{4}{|l|}{ Location } \\
\hline Public & $64(46)$ & $129(28)$ & $<0.001$ \\
\hline Home & $47(34)$ & $282(60)$ & \\
\hline Healthcare & $16(12)$ & $51(11)$ & \\
\hline Other & $11(8)$ & $7(2)$ & \\
\hline Witnessed arrest & $106(77)$ & $325(69)$ & 0.13 \\
\hline Bystander CPR & $77(56)$ & $195(42)$ & 0.004 \\
\hline \multicolumn{4}{|l|}{ Pre-hospital ECG rhythmª) } \\
\hline Shockable & $97(70)$ & $116(25)$ & $<0.001$ \\
\hline Non-shockable & $40(29)$ & $348(74)$ & \\
\hline Pre-hospital defibrillation & $99(72)$ & $125(27)$ & $<0.001$ \\
\hline ED arrival during weekend (Saturday or Sunday) & $47(34)$ & $137(29)$ & 0.33 \\
\hline ED arrival during non-business hours $(<8$ am or $>5 \mathrm{pm})$ & $31(23)$ & $134(29)$ & 0.19 \\
\hline Response time (min) & $6(5-9)$ & $6(5-8)$ & 0.80 \\
\hline Transfer time (min) & $20(14-48)$ & $19(14-30)$ & 0.29 \\
\hline ROSC time (min) & $29(18-43)$ & $34(27-45)$ & 0.001 \\
\hline \multicolumn{4}{|l|}{ Cardiovascular risk factors } \\
\hline Diabetes & $28(20)$ & $109(23)$ & 0.66 \\
\hline Hypertension & $60(44)$ & $182(39)$ & 0.61 \\
\hline Smoking & $83(60)$ & $175(37)$ & $<0.001$ \\
\hline \multicolumn{4}{|l|}{ Hospital course } \\
\hline Intubation & $120(87)$ & $446(95)$ & 0.002 \\
\hline Use of inotropes & $95(69)$ & $361(77)$ & 0.07 \\
\hline Therapeutic hypothermia & $65(47)$ & $100(21)$ & $<0.001$ \\
\hline Temporary pacemaker & $5(4)$ & $5(1)$ & 0.10 \\
\hline Mechanical circulatory support & $39(28)$ & $9(2.2)$ & $<0.001$ \\
\hline IABP & $18(13)$ & $1(0.2)$ & $<0.001$ \\
\hline ECMO & $21(15)$ & $8(2)$ & $<0.001$ \\
\hline Revascularization & $69(50)$ & $15(3)$ & $<0.001$ \\
\hline $\mathrm{PCl}$ & $60(44)$ & $0(0)$ & $<0.001$ \\
\hline Bypass surgery ${ }^{b}$ & $3(2)$ & $2(0.4)$ & 0.14 \\
\hline Thrombolysis & $15(11)$ & $13(3)$ & $<0.001$ \\
\hline
\end{tabular}

Values are presented as median (interquartile range) or number (\%). Six cases without pre-hospital ECG rhythm were excluded from the table.

$C A G$, coronary angiography; CPR, cardiopulmonary resuscitation; ECG, electrocardiography; ED, emergency department; ROSC, return of spontaneous circulation; IABP, intra-aortic balloon pump; ECMO, extracorporeal membrane oxygenation; $\mathrm{PCl}$, percutaneous coronary intervention.

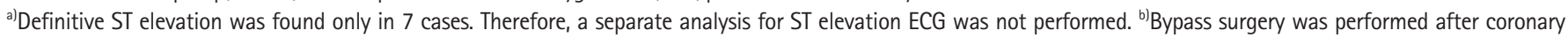
angiography beyond 24 hours.

Table 2. Clinical outcome

\begin{tabular}{lccc}
\hline & $\begin{array}{c}\text { Early CAG } \\
(\mathrm{n}=138)\end{array}$ & $\begin{array}{c}\text { No CAG } \\
(\mathrm{n}=469)\end{array}$ & P-value \\
\hline $\begin{array}{l}\text { Survival at discharge } \\
\text { Cerebral performance category score }\end{array}$ & $91(66)$ & $104(22)$ & $<0.001$ \\
1 & $66(48)$ & $36(8)$ & \\
2 & $6(4)$ & $8(2)$ & \\
3 & $4(3)$ & $15(3)$ & \\
4 & $15(11)$ & $38(8)$ & \\
5 & $47(34)$ & $372(79)$ & \\
$\leq 2$ & $72(52)$ & $44(10)$ & $<0.001$ \\
\hline
\end{tabular}

Values are presented as number (\%).

CAG, coronary angiography. rival and CAG in both the unadjusted and propensity score-matched analyses $(\mathrm{P}<0.05$ for all) (Fig. 3).

\section{DISCUSSION}

In this analysis of a nationwide multicenter registry, propensity score-matched patients who underwent early CAG after OHCA had 2.3-fold higher odds of survival with a favorable neurologic status, compared with patients without CAG.

An organized team approach, including transfer, hypothermia, and interventional procedures, is being emphasized for optimal 
Table 3. Pre-hospital clinical characteristics and hospital course, propensity score-matched

\begin{tabular}{|c|c|c|c|}
\hline & Early CAG $(n=115)$ & No CAG $(n=115)$ & P-value \\
\hline \multicolumn{4}{|l|}{ Pre-hospital presentation } \\
\hline Age $(y r)$ & $57(50-69)$ & $59(46-72)$ & 0.88 \\
\hline Sex, male & $100(87)$ & $94(82)$ & 0.36 \\
\hline \multicolumn{4}{|l|}{ Location } \\
\hline Public & $49(42)$ & $56(49)$ & 0.02 \\
\hline Home & $40(35)$ & $48(42)$ & \\
\hline Healthcare & $16(14)$ & $10(9)$ & \\
\hline Other & $10(9)$ & $1(1)$ & \\
\hline Witnessed arrest & $89(77)$ & $89(77)$ & 0.60 \\
\hline Bystander CPR & $60(52)$ & $64(56)$ & 0.69 \\
\hline \multicolumn{4}{|l|}{ Pre-hospital electrocardiography rhythm } \\
\hline Shockable & $75(69)$ & $65(50)$ & 0.50 \\
\hline Non-shockable & $40(31)$ & $50(50)$ & \\
\hline Pre-hospital defibrillation & $76(66)$ & $80(70)$ & 0.67 \\
\hline ED arrival during weekend (Saturday or Sunday) & $40(35)$ & $35(30)$ & 0.57 \\
\hline ED arrival during non-business hours $(<8$ am or $>5 \mathrm{pm})$ & $25(22)$ & $26(23)$ & 1.00 \\
\hline Response time (min) & $6(5-9)$ & $6(5-8)$ & 0.67 \\
\hline Transfer time (min) & $21(14-46)$ & $20(15-34)$ & 0.97 \\
\hline ROSC time (min) & $29(20-42)$ & $31(22-44)$ & 0.35 \\
\hline \multicolumn{4}{|l|}{ Cardiovascular risk factors } \\
\hline Diabetes & $24(20)$ & $16(14)$ & 0.46 \\
\hline Hypertension & $51(44)$ & $38(33)$ & 0.20 \\
\hline Smoking & $65(57)$ & $57(50)$ & 0.19 \\
\hline \multicolumn{4}{|l|}{ Hospital course } \\
\hline Intubation & $106(92)$ & $107(93)$ & 1.00 \\
\hline Use of inotropic & $81(70)$ & $88(77)$ & 0.37 \\
\hline Therapeutic hypothermia & $48(42)$ & $48(42)$ & 1.00 \\
\hline Temporary pacemaker & $5(4)$ & $1(1)$ & 0.22 \\
\hline Mechanical circulatory support & $35(31)$ & $4(4)$ & $<0.001$ \\
\hline IABP & $16(14)$ & $1(1)$ & $<0.001$ \\
\hline ECMO & $19(17)$ & $3(3)$ & 0.001 \\
\hline Revascularization & $55(48)$ & $3(3)$ & $<0.001$ \\
\hline $\mathrm{PCl}$ & $50(44)$ & $0(0)$ & $<0.001$ \\
\hline Bypass surgery & $3(3)$ & $0(0)$ & 0.25 \\
\hline Thrombolysis & $11(10)$ & $3(3)$ & 0.05 \\
\hline
\end{tabular}

Values are presented as median (interquartile range) or number (\%).

CAG, coronary angiography; CPR, cardiopulmonary resuscitation; ED, emergency department; ROSC, return of spontaneous circulation; IABP, intra-aortic balloon pump; ECMO, extracorporeal membrane oxygenation; $\mathrm{PCl}$, percutaneous coronary intervention.

Table 4. Clinical outcome of propensity score-matched groups

\begin{tabular}{lccc}
\hline & $\begin{array}{c}\text { Early CAG } \\
(n=115)\end{array}$ & $\begin{array}{c}\text { No CAG } \\
(n=115)\end{array}$ & P-value \\
\hline $\begin{array}{l}\text { Survival at discharge } \\
\text { Cerebral performance category score }\end{array}$ & $71(62)$ & $43(37)$ & $<0.001$ \\
1 & $50(43)$ & $21(18)$ & $<0.001$ \\
2 & $6(5)$ & $2(3)$ & \\
3 & $4(3)$ & $7(6)$ & \\
4 & $11(10)$ & $13(11)$ & \\
5 & $44(38)$ & $72(63)$ & \\
$\leq 2$ & $56(49)$ & $23(20)$ & $<0.001$ \\
\hline
\end{tabular}

Values are presented as number (\%). CAG, coronary angiography. post-resuscitation care of OHCA patients. ${ }^{11}$ Performing CAG, which enables immediate confirmation of coronary artery disease followed by revascularization if necessary, has been reported to improve clinical outcomes of OHCA patients, ${ }^{7,9,12-14}$ and was confirmed in this propensity score-matched analysis of a nationwide registry. Among patients who underwent early $C A G$, revascularization was performed in half of the patients, which might be a critical component in the acute care of these patients, potentially leading to better outcomes.

The definition of early CAG was not consistent in prior studies and ranged from 6 to 24 hours. ${ }^{7,9,12-14}$ In this study, we assessed 
Unadjusted

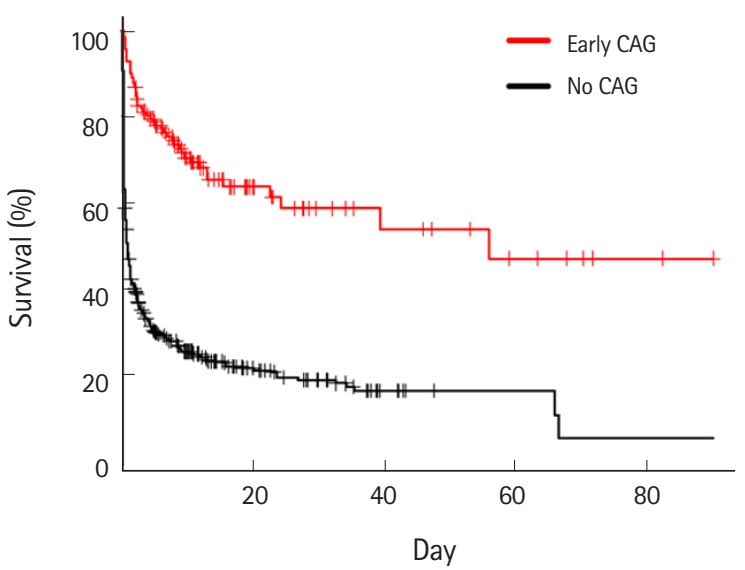

(A)

Unadjusted

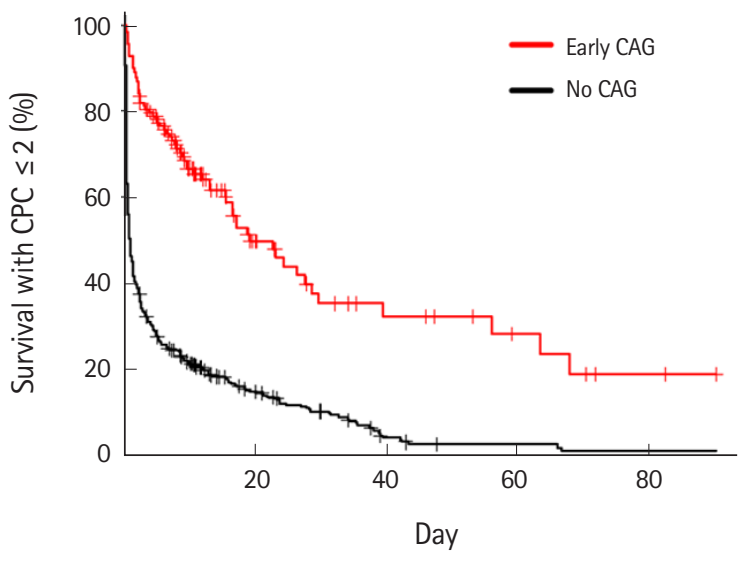

C

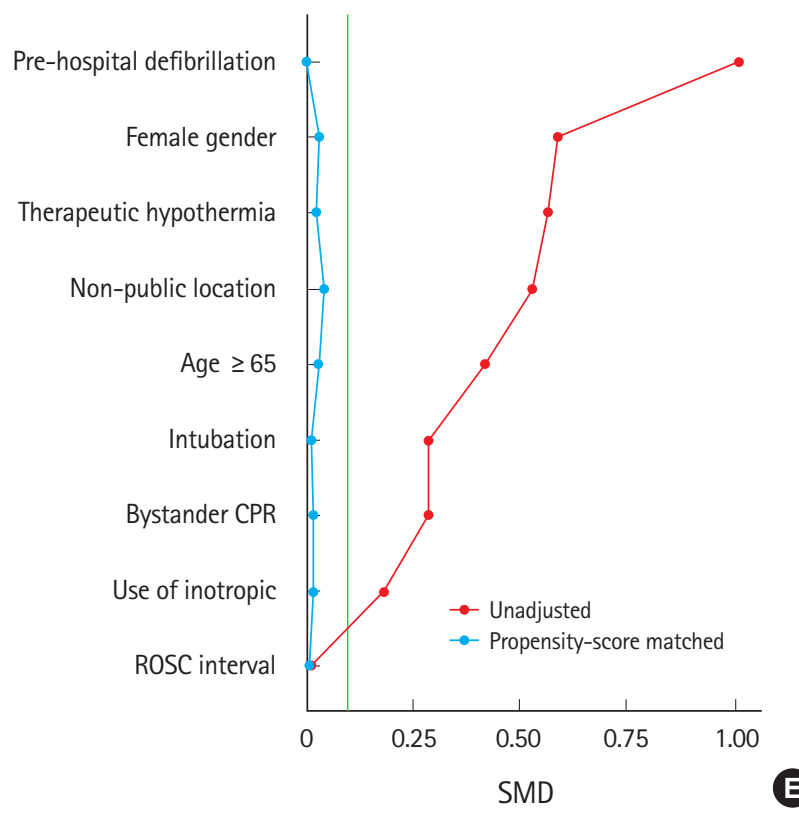

the relationship between the timing of early CAG and the resulting clinical benefits. Both the survival to discharge with favorable neurological status and survival to discharge alone increased ac-
Propensity-score matched

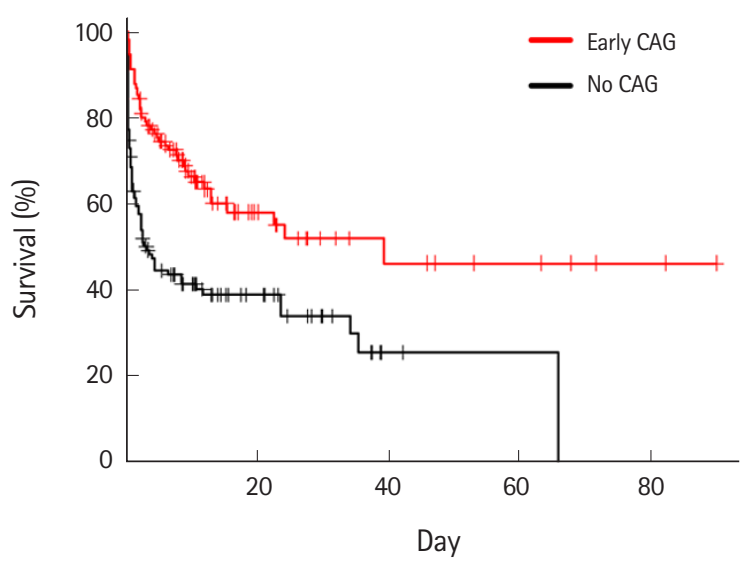

Propensity-score matched

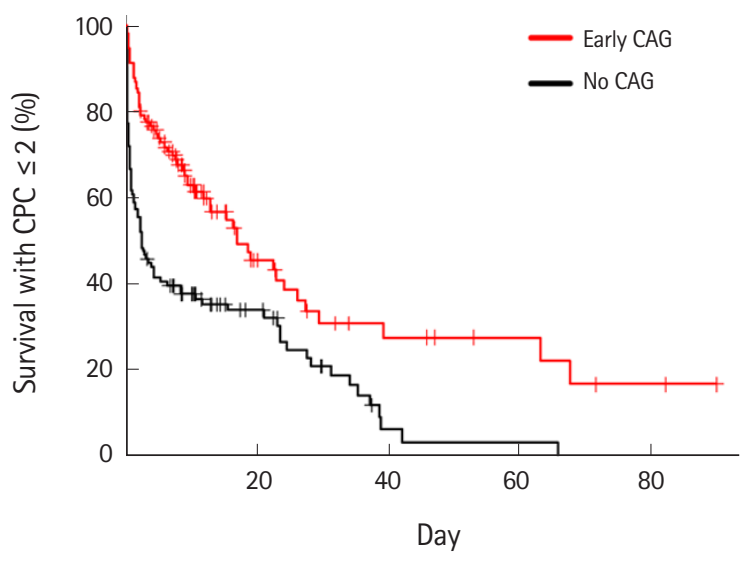

D

Fig. 2. Clinical outcome. (A-D) Unadjusted and propensity scorematched survival analyses. (E) Standardized mean difference between the two groups was reduced to less than 0.1 after propensity score-matching. $\mathrm{CPC}$, cerebral performance category; $\mathrm{CAG}$ coronary angiography; $\mathrm{CPR}$, cardiopulmonary resuscitation; $\mathrm{ROSC}$, return of spontaneous circulation; SMD, standardized mean difference.

cording to the time interval between ED arrival and CAG (Fig. 3). As such, the optimal timing of early CAG for clinical benefit could not be determined. Better clinical outcomes in relatively late CAG 
Table 5. Unadjusted and propensity score-matched associations between coronary angiography and clinical outcomes

\begin{tabular}{|c|c|c|c|c|c|c|}
\hline & $\begin{array}{l}\mathrm{CPC} \leq 2 \text { at discharge } \\
\text { Hazard ratio }(95 \% \mathrm{Cl})\end{array}$ & $\begin{array}{l}\text { Survival at discharge } \\
\text { Hazard ratio }(95 \% \mathrm{Cl})\end{array}$ & P-value & $\begin{array}{l}\mathrm{CPC} \leq 2 \text { at discharge } \\
\text { Odds ratio }(95 \% \mathrm{Cl})\end{array}$ & $\begin{array}{l}\text { Survival at discharge } \\
\text { Odds ratio }(95 \% \mathrm{Cl})\end{array}$ & P-value \\
\hline Unadjusted & $3.6(2.8-4.7)$ & $4.0(3.0-5.5)$ & $<0.001$ & $6.8(4.5-10.3)$ & $10.5(6.8-16.6)$ & $<0.001$ \\
\hline Propensity score-matched & $2.3(1.6-3.1)$ & $2.3(1.6-3.3)$ & $<0.001$ & $3.8(2.1-6.8)$ & $2.7(1.6-4.6)$ & $<0.001$ \\
\hline
\end{tabular}

$\mathrm{CPC}$, cerebral performance category; $\mathrm{Cl}$, confidence interval.

$(\%)$

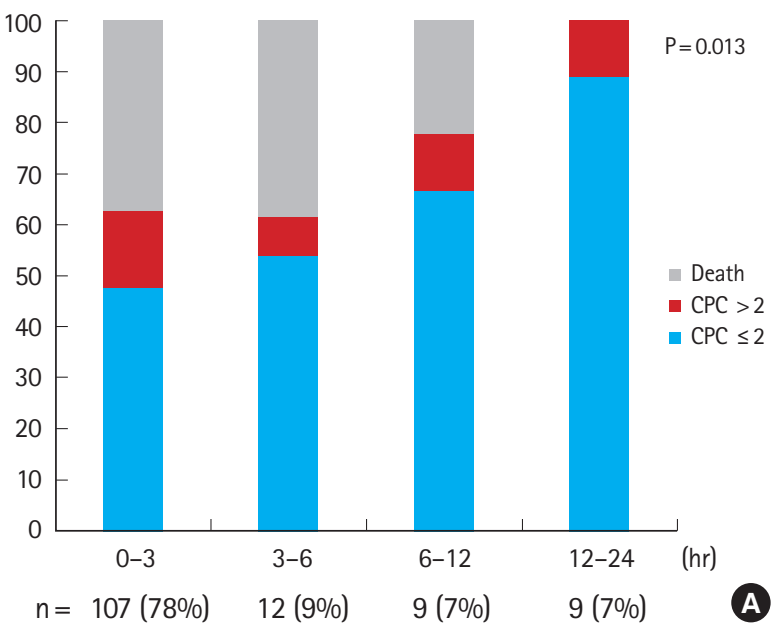

$(\%)$

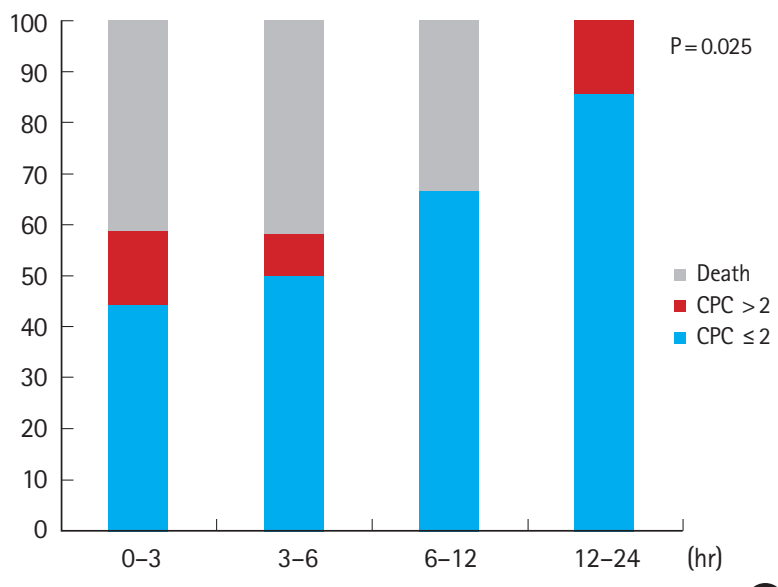

$n=90(78 \%) \quad 12(10 \%) \quad 6(7 \%) \quad 7(6 \%)$

Fig. 3. Timing of coronary angiography and clinical outcome. (A) All patients who underwent early coronary angiography (CAG) and (B) propensity scorematched patients who underwent early CAG. CPC, cerebral performance category.

(between 3 to 24 hours) compared to very early CAG (within 3 hours) might reflect a selection bias, rather than a causal relationship. However, because most CAGs were performed within 3 hours of ED arrival, our results suggest that very early CAG might be important for better clinical outcomes. Further clinical studies are required to determine the optimal timing and maximal benefit of CAG for this extremely high-risk population.

Our study has several limitations. First, although multicenter registry data was used, the study period was relatively short, resulting in a moderate number of patients. Second, the transfer of patients initially sent to hospitals lacking percutaneous coronary intervention was not addressed. Third, the decision regarding CAG was subjective, as determined by physicians in each institute without pre-specified criteria. Fourth, propensity score-matched analysis is insufficient to assess the entire impact of CAG on clinical outcomes and does not account for multiple factors involved in the decision of $C A G$, such as functional status, non-cardiac comorbidities, and family or social factors. Fifth, neurological outcome was not assessed by an independent, blinded neurologist and had a limited follow-up duration. Sixth, despite being a nationwide multicenter registry, our results should not be extrapolated to all OHCA patients. Finally, this study is not a blind randomized study and thus it is possible that physicians performing
CAG in less severe OHCA patients led to more favorable outcomes.

In conclusion, in OHCA patients who achieved ROSC, early CAG was associated with better survival and favorable neurologic outcomes at discharge. There was no optimal CAG timing associated with better clinical outcomes; however, further clinical trials are warranted.

\section{CONFLICT OF INTEREST}

No potential conflict of interest relevant to this article was reported.

\section{ACKNOWLEDGMENTS}

This study was supported by the Korea Centers for Disease Control and Prevention.

\section{REFERENCES}

1. Low $L S$, Kern KB. Importance of coronary artery disease in sudden cardiac death. J Am Heart Assoc 2014;3:e001339.

2. Stecker EC, Teodorescu C, Reinier K, et al. Ischemic heart dis- 
ease diagnosed before sudden cardiac arrest is independently associated with improved survival. J Am Heart Assoc 2014;3: e001160.

3. Priori SG, Blomstrom-Lundqvist C, Mazzanti A, et al. 2015 ESC guidelines for the management of patients with ventricular arrhythmias and the prevention of sudden cardiac death: the Task Force for the Management of Patients with Ventricular Arrhythmias and the Prevention of Sudden Cardiac Death of the European Society of Cardiology (ESC). Endorsed by: Association for European Paediatric and Congenital Cardiology (AEPC). Eur Heart J 2015;36:2793-867.

4. Noc M, Fajadet J, Lassen JF, et al. Invasive coronary treatment strategies for out-of-hospital cardiac arrest: a consensus statement from the European association for percutaneous cardiovascular interventions (EAPCI)/stent for life (SFL) groups. Eurolntervention 2014;10:31-7.

5. Zanuttini D, Armellini I, Nucifora G, et al. Predictive value of electrocardiogram in diagnosing acute coronary artery lesions among patients with out-of-hospital-cardiac-arrest. Resuscitation 2013;84:1250-4.

6. Staer-Jensen $H$, Nakstad ER, Fossum E, et al. Post-resuscitation ECG for selection of patients for immediate coronary angiography in out-of-hospital cardiac arrest. Circ Cardiovasc Interv 2015 Oct 9. https://doi.org/10.1161/CIRCINTERVENTIONS.115.002784.

7. Hollenbeck RD, McPherson JA, Mooney MR, et al. Early cardiac catheterization is associated with improved survival in comatose survivors of cardiac arrest without STEMI. Resuscita- tion 2014;85:88-95.

8. Callaway CW, Schmicker RH, Brown SP, et al. Early coronary angiography and induced hypothermia are associated with survival and functional recovery after out-of-hospital cardiac arrest. Resuscitation 2014;85:657-63.

9. Vyas $A$, Chan PS, Cram $P$, et al. Early coronary angiography and survival after out-of-hospital cardiac arrest. Circ Cardiovasc Interv 2015 Oct 9. https://doi.org/10.1161/CIRCINTERVENTIONS.114.002321.

10. Jennett $B$, Bond $M$. Assessment of outcome after severe brain damage. Lancet 1975;1:480-4.

11. Callaway CW, Donnino MW, Fink EL, et al. Part 8: post-cardiac arrest care: 2015 American Heart Association guidelines update for cardiopulmonary resuscitation and emergency cardiovascular care. Circulation 2015;132:S465-82.

12. Camuglia AC, Randhawa VK, Lavi S, Walters DL. Cardiac catheterization is associated with superior outcomes for survivors of out of hospital cardiac arrest: review and meta-analysis. Resuscitation 2014;85:1533-40.

13. Larsen JM, Ravkilde J. Acute coronary angiography in patients resuscitated from out-of-hospital cardiac arrest: a systematic review and meta-analysis. Resuscitation 2012;83:1427-33.

14. Garcia S, Drexel T, Bekwelem W, et al. Early access to the cardiac catheterization laboratory for patients resuscitated from cardiac arrest due to a shockable rhythm: the Minnesota Resuscitation Consortium twin cities unified protocol. J Am Heart Assoc 2016 Jan 7. https://doi.org/10.1161/JAHA.115.002670. 